\title{
Does early and aggressive management of significant extrusion of the femoral head affect the outcome of Perthes' disease with the age of onset younger than 7 years?
}

\author{
K. A. Singh ${ }^{1} \cdot$ N. Harne ${ }^{1} \cdot$ H. Shah ${ }^{1}$ (1)
}

Received: 23 August 2020 / Accepted: 31 March 2021 / Published online: 18 April 2021

(c) The Author(s) 2021

\begin{abstract}
Background Little literature exists regarding aggressive treatment of the extrusion in the early stage of the disease and the outcome at skeletal maturity. The purpose of the study was to evaluate the outcome of the disease with onset younger than 7 years, treated in the early stage of the disease, with aggressive management of significant extrusion (immediate containment with fixed abduction brace in children less than 5 years and varus derotation osteotomy in older children), and reached skeletal maturity.

Methods All children with the age of onset younger than 7 years of disease during active Perthes disease were prospectively followed. Children with early stages of the disease (modified Elizabethtown classification) and reached skeletal maturity were included ( 68 children). The extrusion of the femur head was calculated by Reimer's migration index on both sides. A migration difference $12 \%$ or above was considered as "significant extrusion". Children without significant extrusion were treated non-operatively; children with significant extrusion were treated with varus derotation osteotomy. The final radiological outcome was assessed by the Stulberg classification and sphericity deviation score (SDS). The independent " $t$ " test and Chi-square test were done to compare the difference between the two groups.

Results The mean age at the onset and the final follow-up was 5.7 years and 15.3 years. The frequency of significant extrusion was $57 \%$. At the final follow-up, an excellent clinical outcome and radiological outcomes (in $88 \%$ hips) were noted. There was no significant difference in the Stulberg groups and SDS (sphericity deviation score) in both groups.

Conclusion The outcome of the children who had the age of onset of the disease less than 7 years was good with early and aggressive management of the extrusion. The reversal of extrusion is associated with a similar result of non-operative children in this age group.

Level of evidence III.
\end{abstract}

Keywords Perthes disease · Age of onset less than 7 years $\cdot$ Containment $\cdot$ Extrusion $\cdot$ SDS

\section{Introduction}

Although the outcome of Perthes disease, which has an age of onset less than 7 years, is generally good, consistent results are not seen even in this young age group [1]. The extent of involvement and extrusion of the femoral head influence the outcome in these children [2]. The extent of

H. Shah

hiteshshah12@gmail.com

1 Department of Paediatric Orthopaedics, Kasturba Hospital, Kasturba Medical College, Manipal Academy of Higher Education, Manipal, Karnataka 576104, India involvement of the femur head cannot be effectively classified in early stage of the disease. Diverse literature exists regarding the frequency of the femur head extrusion in the active stage of disease [3-9]. The significant extrusion during the late stage of fragmentation and the stage of revascularization contributes maximally to the amount of head deformation. The earlier treatment before the advanced stage of fragmentation is associated with a good outcome. Hence, the extrusion of the femoral head is the prime variable that decides the treatment modality in the younger population.

The extent of head involvement is extensively studied [2, 4]. However, very few articles studied the effect of the femur head extrusion in the active stage of the disease. Green et al. showed great influence of the extrusion in the outcome of 
the disease [3]. The significance of the extrusion has never been objectively defined before. The outcome of children (less than 7 years' onset) with Perthes disease at skeletal maturity is poorly reported in the literature. The extrusion of the femur head was aggressively managed in the early stage of the disease in our population. The aggressive management of the extrusion is done with immediate containment as soon as presence of significant extrusion (fixed abduction brace in children less than 5 years and varus derotation osteotomy in older children).

The purpose of the study was to evaluate the outcome of the disease with onset younger than 7 years, treated in the early stage of the disease, with aggressive management of extrusion, and reached skeletal maturity.

\section{Materials and methods}

After obtaining Institutional Ethics Committee permission, all consecutive children with Perthes disease were prospectively studied. Over a period of 15 years, 90 children had disease onset before 7 years of age. The modified Elizabethtown classification was used to stage the disease [4]. The early-stage presentation was defined as the presentation in the stage of avascular necrosis or early fragmentation [10]. The extrusion of the femur head was calculated by Reimer's migration index at the initial presentation and subsequent follow-up [11]. A migration difference $12 \%$ or above was considered as "significant extrusion" (Fig. 1) [12]. A significant extrusion was aggressively managed during the early stage of disease (the stage of avascular necrosis and the stage of early fragmentation).

\section{Treatment protocol}

All children with initial restriction of the range of motion were treated with skin traction till gaining normal range of movements. Children with severe limitation of the range of motion were treated with broomstick cast for 6 weeks. Children without significant extrusion at the initial presentation were treated non-operatively (Fig. 2). They were kept nonweight bearing with axillary crutches. They were followed up at 3 months' interval to observe the extrusion. Without significant extrusion till the advanced stage of fragmentation, they were treated non-operatively.

Children younger than 5 years with significant extrusion were managed with fixed abduction brace (35-degree hip abduction). They were treated with non-weight-bearing walking after 5 years of age till stage IIIb (Fig. 3). Older than 5 years' age with significant extrusion at initial presentation or at subsequent follow-up till the stage of early fragmentation were treated with varus derotation osteotomy and trochanteric epiphysiodesis.

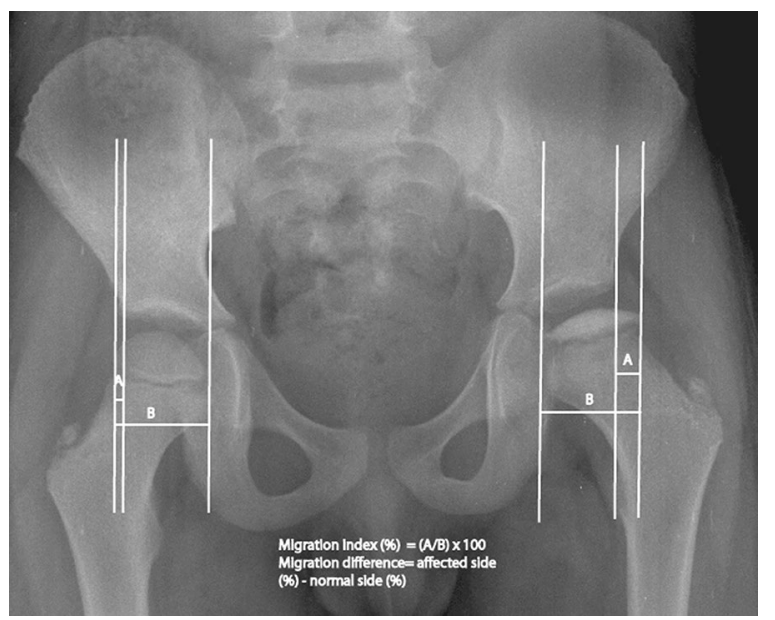

Fig. 1 Illustration of Reimer's migration index on both sides and migration difference calculation

Surgical containment was considered with 20 degrees pre-bend plate with sub-trochanteric open wedge osteotomy [13]. The surgical containment was done only in the early stage of the disease (Fig. 4). All children were kept non-weight bearing with axillary crutches till stage IIIb. Weight bearing was allowed at the stage IIIlb of the disease.

These children were prospectively followed at 3 months interval during the active stage of the disease and thereafter annually till skeletal maturity. Skeletal maturity was defined as children with Oxford grading more than 17 [14]. All their serial radiographs were evaluated. The extent of head involvement was calculated during the stage of fragmentation by Catterall classification [2]. The extent of the head involvement was not considered for the decision making of the treatment.

We included children with early-stage presentation and followed till the skeletal maturity. The children with late presentation and not followed till skeletal maturity were excluded. Sixty-eight children formed the basis of the study. Out of 68 children (77 hip joints) with Perthes disease, nine children had bilateral involvement (all 18 hips got affected before the age of 7 years).

Clinical outcome at skeletal maturity was assessed by the presence of pain, limp, range of motion of the hip. The shape of the femoral head at skeletal maturity was assessed by Stulberg classification [15] and sphericity deviation score [16].

\section{Statistical analysis}

Statistical package for social sciences software for Windows SPSS version 20.0 was used for statistical analysis. The independent " $t$ " test and Chi-square test were used to compare the difference between the two groups. 

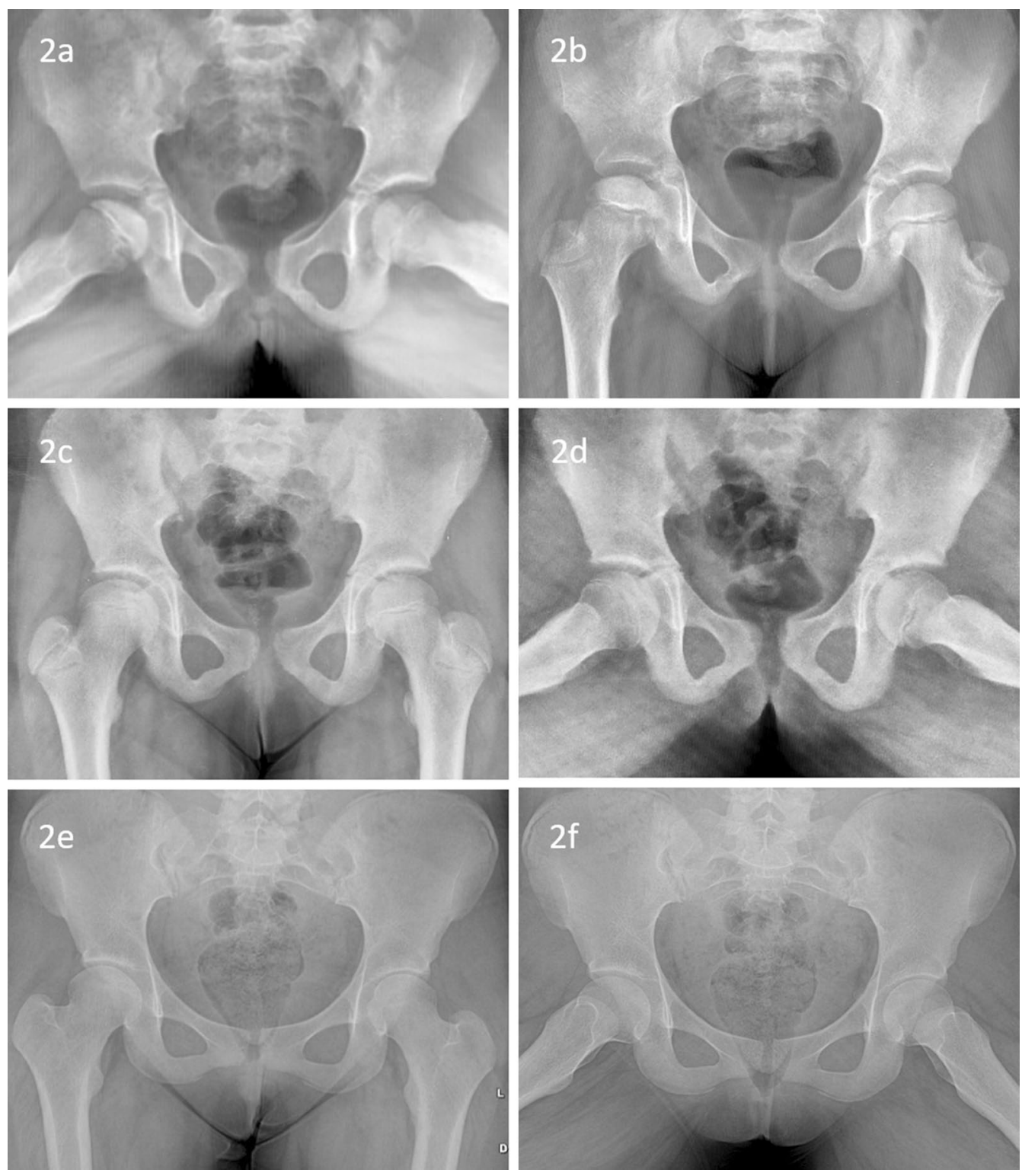

Fig. 2 Anteroposterior (a) and frog-lateral (b) radiographs of a girl with the age of onset 6 years with right side Perthes disease stage $\mathrm{Ib}$ without significant extrusion. With non-operative management, the

\section{Results}

The mean age at the onset was $5.71 \pm 0.87$ years ( $3-7$ years) in 68 children. The frequency of significant extrusion was $57 \%$ in the study. The mean age of the children in both groups was comparable. Boys and girls were equally distributed in both groups. The mean age for the final follow-up was comparable, though the patients in the non-operative group had longer follow-up (Table 1).

Eleven children (12 hip joints) had less than 5 years of age at onset. Five children had a bilateral involvement. Seven out of twelve femur heads had a significant extrusion. Significant disease healed with spherical and congruent hip (c, d). At skeletal maturity, spherical congruent hip was noted $(\mathbf{e}, \mathbf{f})$

extrusion was noted in two hips with unilateral involvement and five hips with bilateral involvement. All these children were treated with a fixed abduction brace. Despite the abduction brace, extrusion increased in 13 months' follow-up, and the second hip also developed Perthes in a girl. This girl underwent bilateral femur head containment surgery (Fig. 5).

Fifty-seven children (65 hip joints) developed Perthes between 5 and 7 years of age. Thirty-seven hips had a significant extrusion. All these hips with a significant extrusion were treated with varus derotation osteotomy and trochanteric epiphysiodesis (Fig. 6). Ninety-six percent of children 

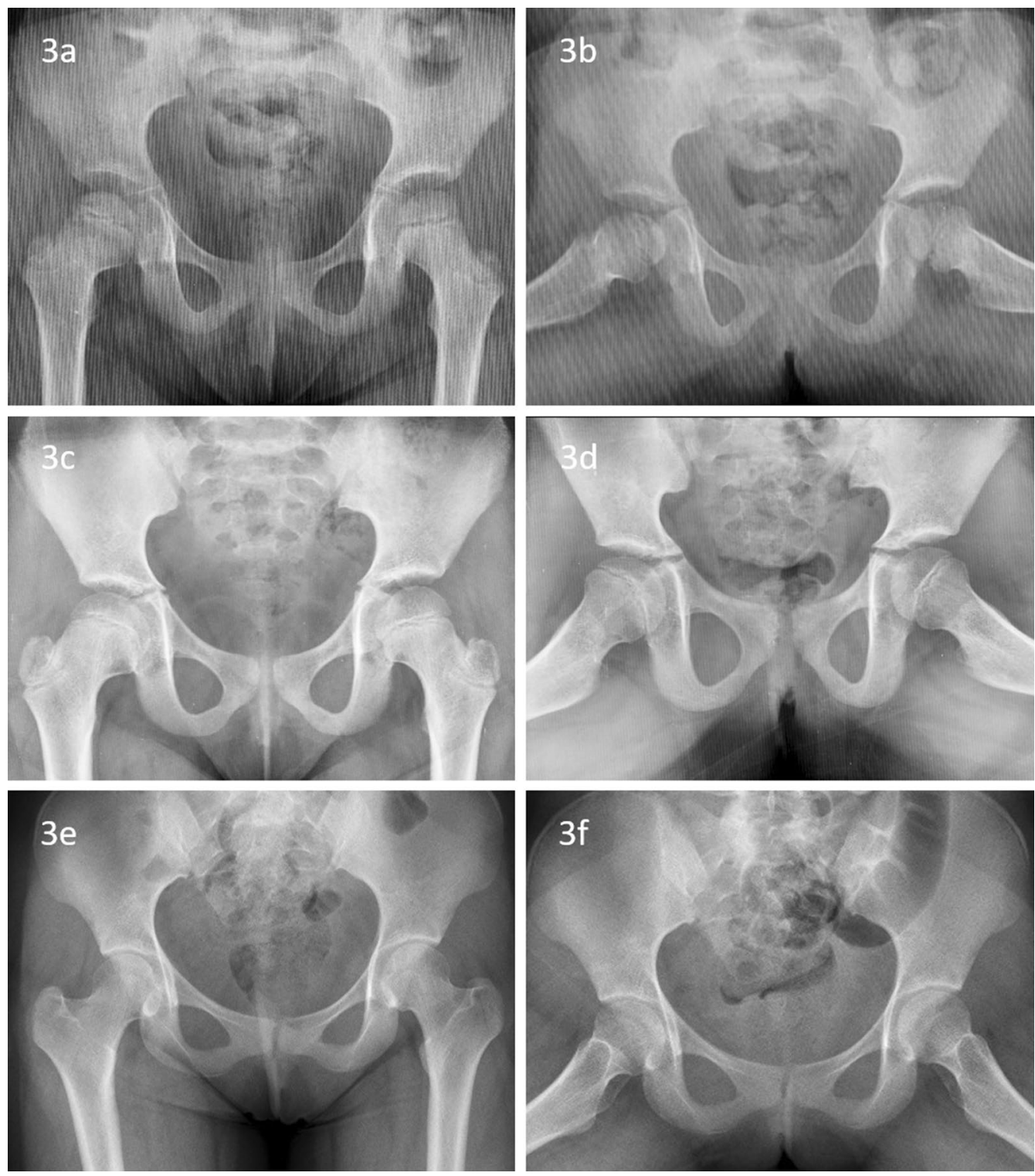

Fig. 3 A girl presented with Perthes disease (age of onset 4.5 years) of right hip (a, b). She was managed with an abduction splint. The femur head was enlarged but spherical and congruent at healed stage (c, d). At 17 years, the femur head was Stulberg Class I hip (e, f)

had more than half involvement during the stage of fragmentation; three hips were not classified due to bypass of the stage of fragmentation. There was no significant difference in the distribution of Catterall IV in both groups. The extent of involvement in both groups was comparable.

An excellent clinical outcome was noted at the final follow-up. No patients had pain, or restriction of range of motion. A mild limp was noted in 4 children. There was no significant difference in clinical outcomes between both groups. Radiographs at skeletal maturity showed good outcomes in $88.3 \%$ hips, and mean SDS was 8.6. All hip joints were congruent. Sixty-eight hips were spherical, whereas nine hips were oval. None of the femur head was flattened or incongruent, indicating an overall good to a fair outcome (Table 2). Comparable Stulberg groups and SDS between the two groups were noted (Figs. 2, 3, 4, 5, and 6). No variable, including the age of onset, gender, the extent of involvement, type of treatment, and significant extrusion at the beginning, significantly affects the radiological outcome at skeletal maturity (Table 2).

\section{Discussion}

The natural history of early-onset and late-onset of the disease is different. The natural history of Perthes disease in the younger population is favorable. However, no consistent 

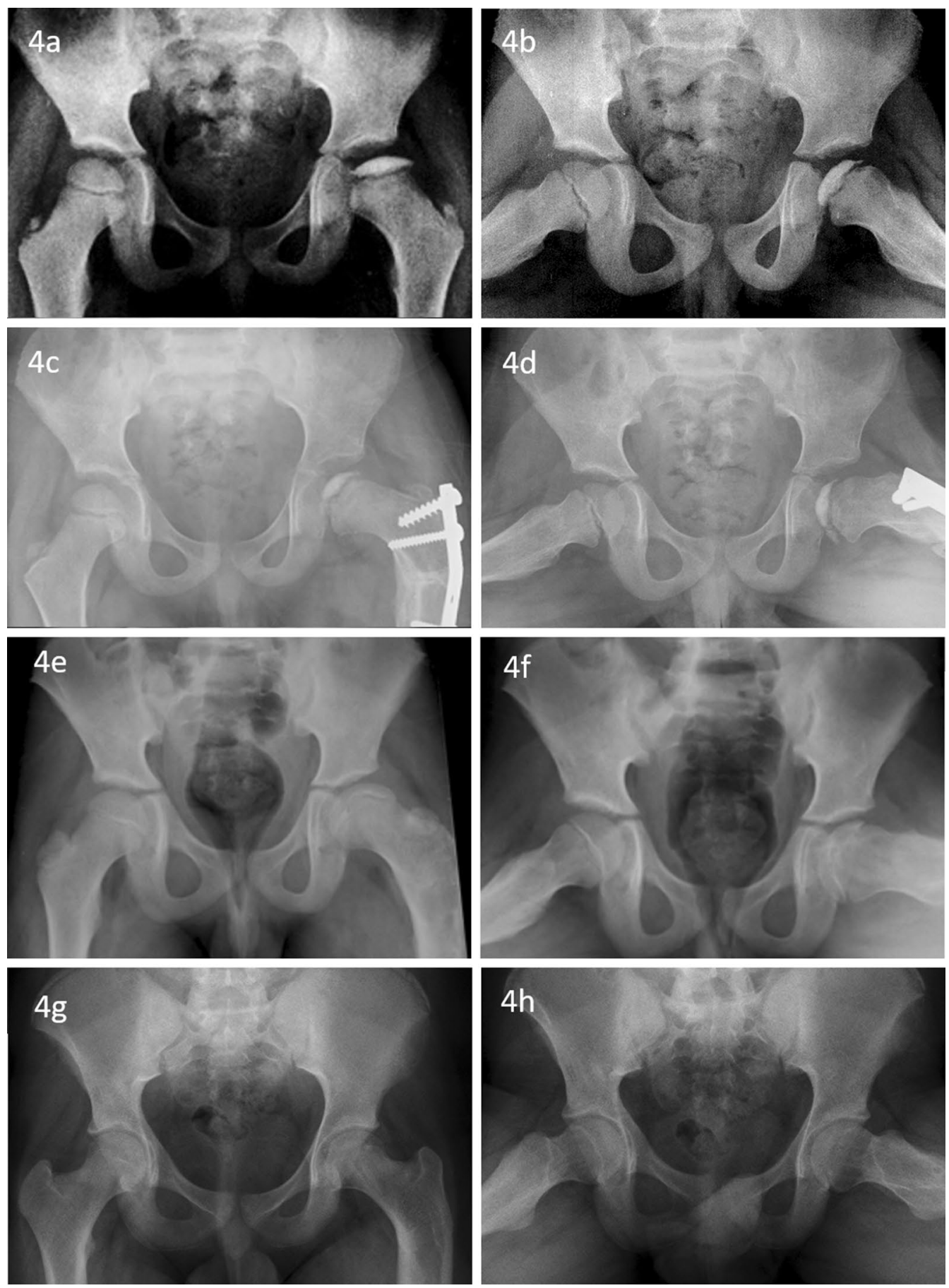

Fig. 4 Anteroposterior (a) and frog-lateral (b) radiographs of a boy with the age of onset 5.5 years with left side Perthes disease (a, b). The Reimer's index was $31.75 \%$ and difference was $12.29 \%$ (a). $\mathrm{He}$

excellent results were noted in the literature. Poor results were noted in one-fourth of the population in children younger than 6 years, with groups III and IV Catterall [6, 17].

The age of onset of disease, the extent of involvement, lateral pillar, and extrusion of the femoral head play a underwent varus derotation osteotomy with trochanteric epiphysiodesis $(\mathbf{c}, \mathbf{d})$. The radiographs at healing $(\mathbf{e}, \mathbf{f})$ and skeletal maturity $(\mathbf{g}, \mathbf{h})$ showed good outcome

significant role in the outcome of the disease [18-20]. Among these variables, the extrusion of the femoral head is only surgeon-dependent variable [19]. The exact frequency of extrusion of the femur head is poorly studied in the literature. The reversal of extrusion is associated with good outcome [21]. 
Table 1 Demographic data of 68 children (77 hips) with Perthes disease onset before 7-year age

\begin{tabular}{|c|c|c|c|c|c|c|c|}
\hline & Total & $\begin{array}{l}\text { Significant extrusion* } \\
(n=44)\end{array}$ & $\begin{array}{l}\text { No significant } \\
\text { extrusion } \\
(n=33)\end{array}$ & $p$ & $\begin{array}{l}\text { Operative group } \\
(n=38 \text { hips })\end{array}$ & $\begin{array}{l}\text { Non-operative group } \\
(n=39 \text { hips })\end{array}$ & $P$ \\
\hline $\begin{array}{l}\text { Age of onset (years) } \\
\text { (Mean } \pm \text { SD) }\end{array}$ & $5.71 \pm 0.87$ & $5.82 \pm 0.91$ & $5.57 \pm 0.82$ & 0.218 & $6.07 \pm 0.67$ & $5.37 \pm 0.92$ & $<0.001$ \\
\hline \multicolumn{8}{|l|}{ The age of onset } \\
\hline$<5$ years & 12 & 7 & 5 & 0.357 & 1 & 11 & $<0.05$ \\
\hline $5-6$ years & 26 & 12 & 14 & & 12 & 14 & \\
\hline $6-7$ years & 39 & 25 & 14 & & 25 & 14 & \\
\hline $\begin{array}{l}\text { Age at follow-up (years) } \\
(\text { Mean } \pm \text { SD) }\end{array}$ & $15.28 \pm 1.95$ & $15.21 \pm 2.23$ & $15.38 \pm 1.5$ & 0.699 & $15.16 \pm 2.16$ & $15.40 \pm 1.73$ & 0.593 \\
\hline $\begin{array}{l}\text { Duration of follow-up } \\
\text { (years) }(\text { Mean } \pm S D)\end{array}$ & $9.32 \pm 1.85$ & $8.93 \pm 1.89$ & $9.84 \pm 1.68$ & $<0.05$ & $8.77 \pm 1.93$ & $9.87 \pm 1.61$ & $<0.05$ \\
\hline \multicolumn{8}{|l|}{ Gender } \\
\hline Boys & 45 (53 hips) & 32 & 21 & 0.394 & 26 & 27 & 0.939 \\
\hline Girls & 23 (24 hips) & 12 & 12 & & 12 & 12 & \\
\hline \multicolumn{8}{|l|}{ Catterall } \\
\hline Group III & 43 & 23 & 20 & 0.218 & 19 & 24 & 0.146 \\
\hline Group IV & 31 & 21 & 10 & & 19 & 12 & \\
\hline
\end{tabular}

*Significant extrusion-migration difference more than $12 \%$ in unilateral involvement and Reimer's index more than $15 \%$ in bilateral Perthes

Varied literature showed different results in different populations. Canavase and Dimeglio, in their study, reported that in 166 hips with a mean age of onset 44 months, 128 (77\%) hips had a good outcome [1]. Rosenfeld, Herring, and Chao analyzed 190 hips with the age of onset less than 6 years and concluded that the prognosis for a patient with the onset of Perthes disease before the age of 6 years was generally favorable, $80 \%$ having good results [7].

Gent et al., in their study of 69 hips with the age of onset less than 6 years, concluded that 45 hips $(64 \%)$ had a good outcome with hips classed Stulberg I and II. The 14 hips (20\%) classed Stulberg III, and the ten hips (14\%) classed Stulberg IV had a poor outcome. They showed overall good results in children with the age of onset fewer than 6 years [9].

Fabry et al. studied 36 hips with Perthes disease. Of those with severe involvement, seven were in Catterall group III and 16 in group IV. At skeletal maturity, they found that $44 \%$ had good, $22 \%$ fair, and $33 \%$ poor results according to the Stulberg groups. Hence, they stated that a young age did not protect from the severe disease [6]. Snyder reported poor results in $43 \%$ of children with onset less than 5 years of age [8]. Nakamura, Kamegaya et al. assessed 114 hips in patients with the age of onset less than 6 years in which good outcome was observed in 72 hips (63\%) with onset before 6 years of age [22]. The current study is compared with similar studies in the literature (Table 3 ).

There were 24 female hips out of 77 included in this study. This is an atypical sex ratio for Perthes' disease compared to almost all other studies. With more advanced skeletal maturation for the same chronological age, the high proportion of females could have worse results; we did not find the worst results in females (Fig. 6).

The effect of the extent of head involvement is well known. The poorer results were attributed to the severe involvement of the head. Most of the time, more severe cases were selected for surgery. As the extent of the involvement is categorized in the advanced stage of fragmentation, the extent of head involvement was not considered for decision making in this study. However, all children had more than $50 \%$ of head involvement. The frequency of Catterall groups was statistically comparable in both groups.

\section{The extrusion of the femoral head}

The concept of "extrusion" is one of the signs of "head at risk" described by Catterall [2]. Green et al. first studied the effect of epiphyseal extrusion in the prognosis of Perthes disease [3]. They found more than $20 \%$ extrusion is associated with poor results. More than $20 \%$ extrusion in even Catterall group II had $40 \%$ good results. Only $8 \%$ of hips showed good results with $20 \%$ or more extrusion in Catterall group III/IV. The poor results were associated with more than $20 \%$ extrusion of the epiphysis. However, both studies did not describe the applicability with the stage of the disease. Coxa magna is associated with poor outcome. The coxa manga can present like the extrusion of the femur head in the late stage of the disease. Epiphyseal extrusion happens during the stage of avascular necrosis or the stage of fragmentation. The 

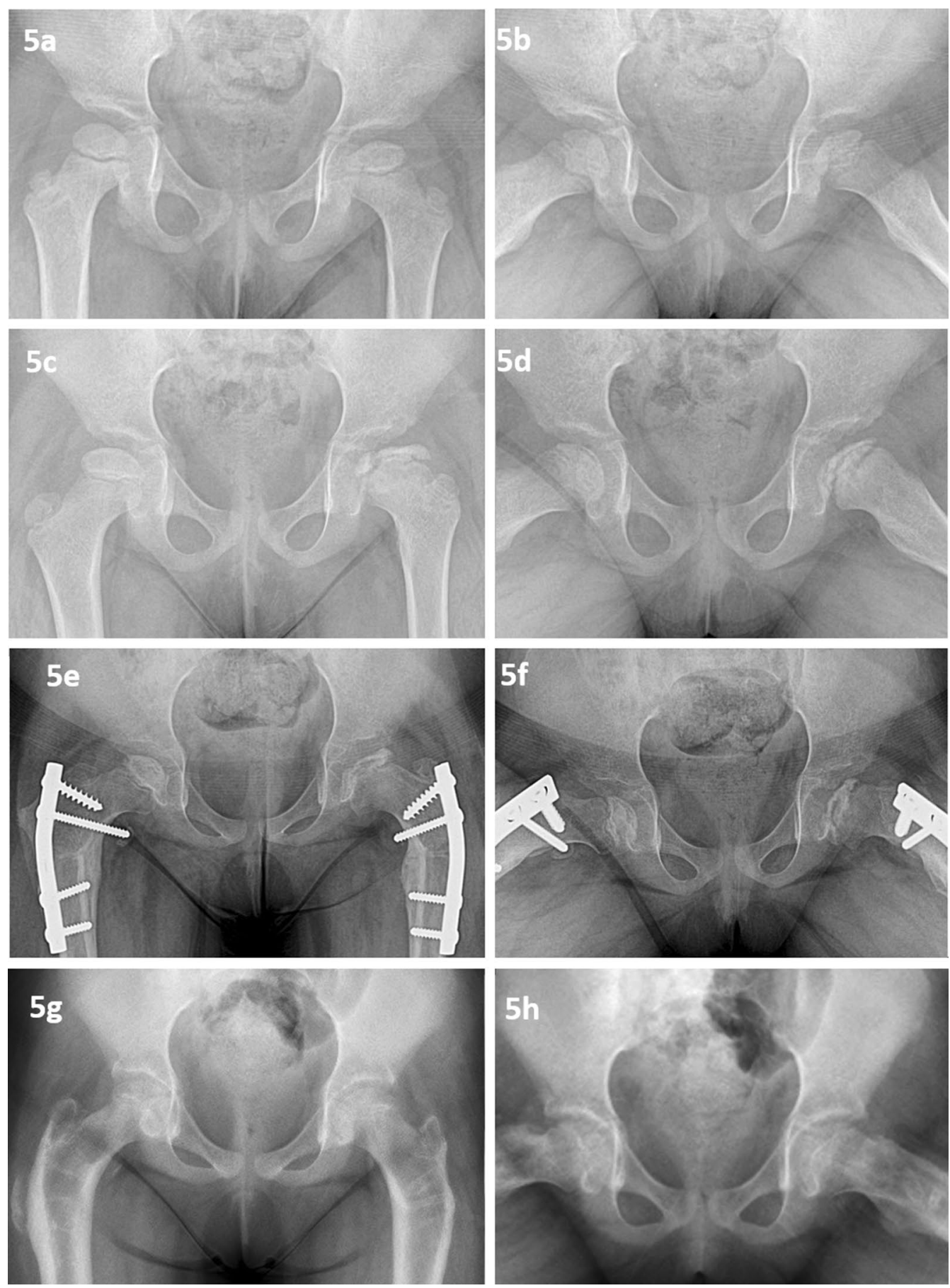

Fig. 5 A girl presented with left hip Perthes with onset at 4.8 years and $11.44 \%$ extrusion $(\mathbf{a}, \mathbf{b})$. She was managed with abduction brace. Thirteen months later, right hip developed Perthes and extrusion in

intervention in the early stage would prevent irreversible deformation of the femoral head. The intervention after irreversible changes would be too late for the prevention of deformation.

No study in the literature objectively quantifies the percentage difference to define the surgical containment. left hip increased to $36.10 \%$ (c, d). Both hips required Varus derotation osteotomy and trochanteric epiphyseodesis (e, f). Both hips healed to spherical congruent hips $(\mathbf{g}, \mathbf{h})$

Eklöf et al. evaluated normal radiographs in all pediatric age groups [12]. They showed a difference of 12 or more percentage compared to the normal side was regarded as abnormal/subluxation. Hence, a difference of $12 \%$ or more migration was chosen as significant extrusion and the segregating factor for surgical indication. 

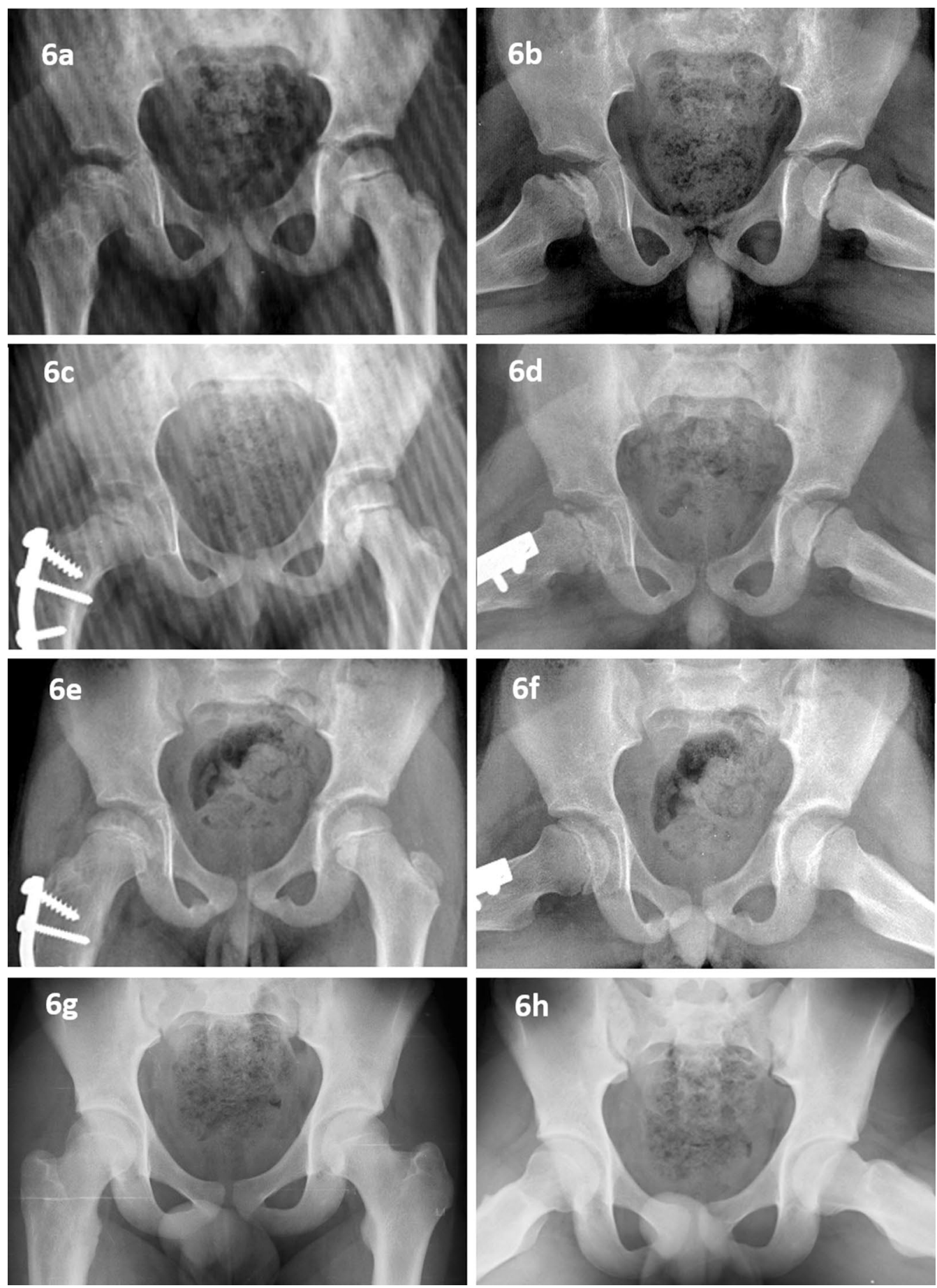

Fig. 6 A 6.5-year boy presented with right hip Perthes disease in early stage with a significant extrusion $(\mathbf{a}, \mathbf{b})$. He underwent varus derotation osteotomy and trochanteric epiphysiodesis of right femur

The age of onset of disease, the extent of involvement, lateral pillar, and extrusion of the femoral head play a significant role in the outcome of the disease [17]. In this population, the younger age of onset is favorable. The extent of involvement and the lateral pillar are only with 20-degree pre-bend plate (c, d). At skeletal maturity, good outcome (Stulberg Class II) was noted (e-h)

classified in the advanced stage of fragmentation. The natural history of the disease cannot be altered by all non-dependent variables. Hence, the extrusion of the femoral head is only the surgeon-dependent variable. This study shows the usefulness of the surgeon-dependent 
Table 2 Radiological outcome of Perthes children with the age of onset less than 7 years

\begin{tabular}{|c|c|c|c|c|c|c|}
\hline & \multicolumn{3}{|l|}{ Stulberg } & \multirow[t]{2}{*}{$P$} & \multirow{2}{*}{$\begin{array}{l}\text { SDS } \\
(\text { Mean } \pm \text { SD })\end{array}$} & \multirow[t]{2}{*}{$P$} \\
\hline & I & II & III & & & \\
\hline All patients ( $n=77$ hip joints) & 33 & 35 & 9 & - & $8.64 \pm 10.82$ & - \\
\hline \multicolumn{7}{|l|}{ Gender } \\
\hline Boys $(n=53)$ & 23 & 26 & 4 & 0.224 & $7.62 \pm 7.99$ & 0.332 \\
\hline Girls $(n=24)$ & 10 & 9 & 5 & & $10.89 \pm 15.32$ & \\
\hline Age at onset Years (Mean \pm SD) & $5.56 \pm 0.87$ & $5.75 \pm 0.90$ & $6.17 \pm 0.65$ & 0.172 & $0.079 *$ & 0.493 \\
\hline \multicolumn{7}{|l|}{ Catterall } \\
\hline Group III $(n=43)$ & 23 & 16 & 4 & 0.111 & $7.39 \pm 7.99$ & 0.501 \\
\hline Group IV $(n=31)$ & 9 & 18 & 4 & & $8.74 \pm 9.09$ & \\
\hline \multicolumn{7}{|l|}{ Treatment } \\
\hline Non-operative $(n=39)$ & 22 & 14 & 3 & 0.055 & $9.36 \pm 12.20$ & 0.556 \\
\hline Operative $(n=38)$ & 11 & 21 & 6 & & $7.90 \pm 9.29$ & \\
\hline \multicolumn{7}{|l|}{ Extrusion } \\
\hline Significant extrusion $(n=44)$ & 15 & 23 & 6 & 0.199 & $7.15 \pm 8.85$ & 0.165 \\
\hline No significant extrusion $(n=33)$ & 18 & 12 & 3 & & $10.62 \pm 12.87$ & \\
\hline
\end{tabular}

*Pearson correlation

\begin{tabular}{|c|c|c|c|c|c|c|}
\hline Author & $\begin{array}{l}\text { Journal } \\
\text { year }\end{array}$ & $\begin{array}{l}\text { Total } \\
\text { number of } \\
\text { children }\end{array}$ & $\begin{array}{l}\text { Total } \\
\text { number of } \\
\text { hips }\end{array}$ & $\begin{array}{l}\text { Good results } \\
\text { Stulberg I/II } \\
N \\
\%\end{array}$ & $\begin{array}{l}\text { Fair results } \\
\text { Stulberg III } \\
N \\
\%\end{array}$ & $\begin{array}{l}\text { Poor results } \\
\text { Stulberg IV/V } \\
N \\
\%\end{array}$ \\
\hline Nakamura et al. [22] & $\begin{array}{l}\text { JPO } \\
2015\end{array}$ & 100 & 114 & $\begin{array}{l}72 \\
63 \%\end{array}$ & $\begin{array}{l}28 \\
25 \%\end{array}$ & $\begin{array}{l}14 \\
12 \%\end{array}$ \\
\hline $\begin{array}{l}\text { Canavese and } \\
\text { Dimeglio [1] }\end{array}$ & $\begin{array}{l}\text { JBJS Br } \\
2008\end{array}$ & 146 & 166 & $\begin{array}{l}78 \\
67 \%\end{array}$ & $\begin{array}{l}26 \\
22 \%\end{array}$ & $\begin{array}{l}12 \\
11 \%\end{array}$ \\
\hline Gent et al. [9] & $\begin{array}{l}\text { JCO } \\
2007\end{array}$ & 67 & 69 & $\begin{array}{l}45 \\
65 \%\end{array}$ & $\begin{array}{l}14 \\
20 \%\end{array}$ & $\begin{array}{l}10 \\
15 \%\end{array}$ \\
\hline Rosenfeld et al. [7] & $\begin{array}{l}\text { JBJS Am } \\
2007\end{array}$ & 160 & 164 & $\begin{array}{l}131 \\
80 \%\end{array}$ & $\begin{array}{l}14 \\
8 \%\end{array}$ & $\begin{array}{l}19 \\
12 \%\end{array}$ \\
\hline Herring et al. [5] & $\begin{array}{l}\text { JBJS Am } \\
2004\end{array}$ & 176 & 180 & $\begin{array}{l}109 \\
61 \%\end{array}$ & $\begin{array}{l}54 \\
30 \%\end{array}$ & $\begin{array}{l}17 \\
9 \%\end{array}$ \\
\hline Fabry et al. [6] & $\begin{array}{l}\text { JPO B } \\
2003\end{array}$ & 30 & 36 & $\begin{array}{l}16 \\
45 \%\end{array}$ & $\begin{array}{l}8 \\
23 \%\end{array}$ & $\begin{array}{l}12 \\
33 \%\end{array}$ \\
\hline Present study & 2021 & 68 & 77 & $\begin{array}{l}68 \\
88.3 \%\end{array}$ & $\begin{array}{l}9 \\
11.7 \%\end{array}$ & 0 \\
\hline
\end{tabular}

Table 3 Comparison of results in younger children with Perthes disease containment. Earlier studies showed no difference associated with or without non-weight bearing. However, a recent study on immature pigs showed non-weight bearing decreased deformity of the femoral head and increased revascularization rate [23]. The study simulates nonweight-bearing crutch walking than absolute bed rest. However, the local non-weight bearing must be prolonged until the advanced stage of revascularization to get the benefit of non-weight bearing. Few clinical studies with prolonged non-weight bearing showed good results of hip and mechanical alignment of the knee [24, 25].

In this study, $88.3 \%$ of good results (Stulberg I or II) were achieved in children younger than 7 years. The frequency of more extrusion was noted higher in older children than
There is a lot of controversy regarding the impact of non- 
younger children. The incidence of more extrusion was observed higher in Catterall group IV.

The possibility of poor outcome in the Perthes disease might be related to extrusion of the epiphysis in localized manifestation of generalized disease. These children do no manifest the whole syndromic criteria of the disease. These children might be the carrier to the connective tissue disorder due to defective extracellular matrix as seen with COMP, COL2A1, COL9A1, COL9A2, etc. genetic mutation [26-29]. Whole exome sequencing with detailed genome analysis in such children might help to differentiate Perthes disease with localized manifestation of skeletal dysplasia [30].

\section{The uniqueness of the study}

The present study reports excellent results in three forth of children population. Poor results (Stulberg IV and V) are not observed in the current study. The extent of involvement of the femur head is similar to other studies. The reason for the study's excellent and fair results is the aggressive treatment of the extrusion of disease in the early stage of the disease with prolonged non-weight bearing until stage IIIb. The extent of involvement and severity of collapse lead to poor results in Perthes disease irrespective of the age of onset of the disease. If we can avoid the severity of collapse and maintain the head's containment, it would be associated with good results. Hence, the poor results, like Stulberg IV/V, were not observed in this study.

\section{Limitation of the study}

The children with significant extrusion were treated with containment in this study. Ideally, natural history can be studied without any intervention. However, due to previous experience, the intervention was justified to prevent poor outcomes. Further studies are required to detect the exact amount of extrusion or \% difference between both sides to treat the children optimally.

\section{Conclusion}

The outcome of the children who had the age of onset of the disease less than 7 years was good with early and aggressive management of the extrusion. The reversal of extrusion is associated with a similar result of non-operative children in this age group.
Authors contribution All authors contributed to the study conception and design. Material preparation, data collection, and analysis were performed by KAS, NH, and HS. The first draft of the manuscript was written by $\mathrm{HS}$ and all authors commented on previous versions of the manuscript. All authors read and approved the final manuscript.

Funding Open access funding provided by Manipal Academy of Higher Education, Manipal. This research did not receive any specific grant from funding agencies in the public, commercial, or not-for-profit sectors.

Declaration

Conflict of interest The authors declare that they have no conflict of interest.

Open Access This article is licensed under a Creative Commons Attribution 4.0 International License, which permits use, sharing, adaptation, distribution and reproduction in any medium or format, as long as you give appropriate credit to the original author(s) and the source, provide a link to the Creative Commons licence, and indicate if changes were made. The images or other third party material in this article are included in the article's Creative Commons licence, unless indicated otherwise in a credit line to the material. If material is not included in the article's Creative Commons licence and your intended use is not permitted by statutory regulation or exceeds the permitted use, you will need to obtain permission directly from the copyright holder. To view a copy of this licence, visit http://creativecommons.org/licenses/by/4.0/.

\section{References}

1. Canavese F, Dimeglio A (2008) Perthes' disease: prognosis in children under six years of age. J Bone Joint Surg Br 90(7):940 945. https://doi.org/10.1302/0301-620X.90B7.20691

2. Catterall A (1971) The natural history of Perthes' disease. J Bone Joint Surg Br 53(1):37-53

3. Green NE, Beauchamp RD, Griffin PP (1981) Epiphyseal extrusion as a prognostic index in Legg-Calvé-Perthes disease. J Bone Joint Surg Am 63(6):900-905

4. Joseph B, Varghese G, Mulpuri K, Narasimha Rao K, Nair NS (2003) Natural evolution of Perthes disease: a study of 610 children under 12 years of age at disease onset. J Pediatr Orthop 23(5):590-600. https://doi.org/10.1097/00004694-20030 9000-00005

5. Herring JA, Kim HT, Browne R (2004) Legg-Calve-Perthes disease. Part II: prospective multicenter study of the effect of treatment on outcome. J Bone Joint Surg Am 86(10):2121-2134

6. Fabry K, Fabry G, Moens P (2003) Legg-Calvé-Perthes disease in patients under 5 years of age does not always result in a good outcome Personal experience and meta-analysis of the literature. $\mathrm{J}$ Pediatr Orthop B 12(3):222-227. https://doi.org/10.1097/01.bpb. 0000049583.53117.f7

7. Rosenfeld SB, Herring JA, Chao JC (2007) Legg-calve-perthes disease: a review of cases with onset before six years of age. $\mathrm{J}$ Bone Joint Surg Am 89(12):2712-2722. https://doi.org/10.2106/ JBJS.G.00191

8. Snyder CR (1975) Legg-Perthes disease in the young hip—does it necessarily do well? J Bone Joint Surg Am 57(6):751-759 
9. Gent E, Antapur P, Mehta RL, Sudheer VM, Clarke NM (2007) Predicting the outcome of Legg-Calve-Perthes disease in children under 6 years old [published correction appears in J Child Orthop. 2007 Jul;1(2):159]. J Child Orthop 1(1):27-32. https://doi.org/10. 1007/s11832-007-0007-7

10. Joseph B, Rao N, Mulpuri K, Varghese G, Nair S (2005) How does a femoral varus osteotomy alter the natural evolution of Perthes' disease? J Pediatr Orthop B 14(1):10-15. https://doi.org/10.1097/ 01202412-200501000-00002

11. Reimers J (1980) The stability of the hip in children. A radiological study of the results of muscle surgery in cerebral palsy. Acta Orthop Scand Suppl 184:1-100. https://doi.org/10.3109/ort.1980. 51.suppl-184.01

12. Eklöf O, Ringertz H, Samuelsson L (1988) The percentage of migration as indicator of femoral head position. Acta Radiol 29(3):363-366

13. Tercier S, Shah H, Siddesh ND, Joseph B (2013) Does proximal femoral varus osteotomy in Legg-Calvé-Perthes disease predispose to angular mal-alignment of the knee? A clinical and radiographic study at skeletal maturity. J Child Orthop 7(3):205-211. https://doi.org/10.1007/s11832-013-0487-6

14. Shah H, Siddesh ND, Joseph B (2008) To what extent does remodeling of the proximal femur and the acetabulum occur between disease healing and skeletal maturity in Perthes disease? A radiological study. J Pediatr Orthop 28(7):711-716. https://doi.org/10. 1097/BPO.0b013e31818456dc

15. Stulberg SD, Cooperman DR, Wallensten R (1981) The natural history of Legg-Calvé-Perthes disease. J Bone Joint Surg Am 63(7):1095-1108

16. Shah H, Siddesh ND, Pai H, Tercier S, Joseph B (2013) Quantitative measures for evaluating the radiographic outcome of LeggCalvé-Perthes disease. J Bone Joint Surg Am 95(4):354-361. https://doi.org/10.2106/JBJS.L.00172

17. Joseph B (2011) Natural history of early onset and late-onset Legg-Calve-Perthes disease. J Pediatr Orthop 31(2 Suppl):S152S155. https://doi.org/10.1097/BPO.0b013e318223b423

18. Schoenecker PL, Stone JW, Capelli AM (1993) Legg-Perthes disease in children under 6 years old. Orthop Rev 22(2):201-208

19. Joseph B (2011) Prognostic factors and outcome measures in Perthes disease. Orthop Clin North Am. 42(3):303. https://doi. org/10.1016/j.ocl.2011.03.004

20. Joseph B, Price CT (2011) Principles of containment treatment aimed at preventing femoral head deformation in Perthes disease. Orthop Clin North Am 42(3):317-vi. https://doi.org/10.1016/j.ocl. 2011.04.001

21. Mintowt-Czyz W, Tayton K (1983) Indication for weight relief and containment in the treatment of perthes' disease. Acta Orthop
Scand 54(3):439-445. https://doi.org/10.3109/174536783089965 98

22. Nakamura J, Kamegaya M, Saisu T, Kakizaki J, Hagiwara S, Ohtori S, Orita S, Takahashi K (2015) Outcome of patients with Legg-Calvé-Perthes onset before 6 years of age. J Pediatr Orthop 35(2):144-150. https://doi.org/10.1097/BPO.0000000000000246

23. Kim HK, Aruwajoye O, Stetler J, Stall A (2012) Effects of nonweight-bearing on the immature femoral head following ischemic osteonecrosis: an experimental investigation in immature pigs. $\mathrm{J}$ Bone Joint Surg Am 94(24):2228-2237. https://doi.org/10.2106/ JBJS.L.00300

24. Bellyei A, Mike G (1991) Weight bearing in Perthes' disease. Orthopedics 14(1):19-22

25. Iwamoto M, Nakashima Y, Nakamura T, Kohno Y, Yamaguchi R, Takamura K (2018) Clinical outcomes of conservative treatment with a non-weight-bearing abduction brace for Legg-CalvéPerthes disease. J Orthop Sci 23(1):156-160. https://doi.org/10. 1016/j.jos.2017.09.012

26. Dasa V, Eastwood JRB, Podgorski M, Park H, Blackstock C, Antoshchenko T, Rogala P, Bieganski T, Jazwinski SM, CzarnyRatajczak M (2019) Exome sequencing reveals a novel COL2A1 mutation implicated in multiple epiphyseal dysplasia. Am J Med Genet A 179(4):534-541. https://doi.org/10.1002/ajmg.a.61049

27. Kenet G, Ezra E, Wientroub S, Steinberg DM, Rosenberg N, Waldman D, Hayek S (2008) Perthes' disease and the search for genetic associations: collagen mutations, Gaucher's disease and thrombophilia. J Bone Joint Surg Br 90(11):1507-11. https://doi. org/10.1302/0301-620X.90B11.20318

28. Li N, Yu J, Cao X, Wu QY, Li WW, Li TF, Zhang C, Cui YX, Li XJ, Yin ZM, Xia XY (2014) A novel p. Gly630Ser mutation of COL2A1 in a Chinese family with presentations of Legg-CalvéPerthes disease or avascular necrosis of the femoral head. PLoS ONE 9(6):e100505. https://doi.org/10.1371/journal.pone.01005 05

29. Su P, Li R, Liu S, Zhou Y, Wang X, Patil N, Mow CS, Mason JC, Huang D, Wang Y (2008) Age at onset-dependent presentations of premature hip osteoarthritis, avascular necrosis of the femoral head, or Legg-Calvé-Perthes disease in a single family, consequent upon a p. Gly1170Ser mutation of COL2A1. Arthritis Rheum 58(6):1701-6. https://doi.org/10.1002/art.23491

30. Pavone V, Chisari E, Vescio A, Lizzio C, Sessa G, Testa G (2019) Aetiology of Legg-Calvé-Perthes disease: a systematic review. World J Orthop 10(3):145-165. https://doi.org/10.5312/wjo.v10. i3.145

Publisher's Note Springer Nature remains neutral with regard to jurisdictional claims in published maps and institutional affiliations. 